\title{
ATP serves an anti-inflammatory role by enhancing $\beta$-defensin-2 response in acute pneumonia of rat
}

\author{
ZHENWEI SHEN $^{1 *}, \mathrm{YUN}_{\mathrm{ZHOU}}^{2}, \mathrm{LE} \mathrm{QU}^{3}$ and HAN LEI ${ }^{4 *}$ \\ ${ }^{1}$ Intensive Care Unit, Shanghai International Medical Center, Shanghai 201318; \\ Departments of ${ }^{2}$ Cardiology and ${ }^{3}$ Cadre, Chinese Traditional Medical Hospital Affiliated to Xinjiang Medical University, \\ Urumqi, Xinjiang 830000; ${ }^{4}$ Department of Respiratory Medicine, Shanghai East Hospital, Shanghai 200120, P.R. China
}

Received February 14, 2017; Accepted March 31, 2017

DOI: $10.3892 /$ br.2017.906

\begin{abstract}
The aim of the current study was to evaluate the effect of ATP on the expression of rat $\beta$-defensin- 2 (rBD-2) in a time-dependent manner, as well as its therapeutic value in an acute pneumonia rat model. A total of 30 rats as a treatment group and 30 as a control group were treated with the same dose of ATP and normal saline, respectively, lung tissues were isolated from rat and expression of rBD-2 mRNA was assessed with reverse transcription-quantitative polymerase chain reaction (RT-qPCR) at 12, 24 and $36 \mathrm{~h}$ following treatment. Rats were divided into five groups: The control group treated with normal saline, the Pseudomonas aeruginosa (PA) infected group, group treated with ATP, group treated with cephalosporins, and the group treated with both ATP and cephalosporins. At $24 \mathrm{~h}$ following treatment, rat serum and lung tissues were collected for assessment of histological changes, and alterations to expression of the rBD-2 protein by immunohistochemistry, expression of tumor necrosis factor (TNF)- $\alpha$ and interleukin (IL)- 6 proteins by ELISA. RT-qPCR results indicated that the expression of $\mathrm{rBD}-2$ mRNA was upregulated in response to ATP stimulation in lung tissues of rat, reaching its highest peak at $24 \mathrm{~h}$. Immunohistochemistry demonstrated that ATP treatment enhanced the expression of rBD-2 protein in rat lungs. Ceftazidime and ATP protected lungs from infection of PA and reduced the pathological damage of the lung. Overexpression of rBD-2 by ATP led to decreased protein expression of TNF- $\alpha$ and IL- 6 in lung tissues and serum. ATP upregulates the expression of $\mathrm{rBD}-2$ and serves an anti-inflammatory role in the acute pneumonia of a rat model.
\end{abstract}

Correspondence to: Dr Han Lei, Department of Respiratory Medicine, Shanghai East Hospital, 150 Jimo Road, Pudong New Area, Shanghai 200120, P.R. China

E-mail: hanlei022@163.com

*Contributed equally

Key words: acute pneumonia, $\beta$-defensin-2, ATP, cephalosporins

\section{Introduction}

$\beta$-defensins (BDs) are cationic peptides which present broad-spectrum antimicrobial activities against bacteria, fungi and viruses (1). To date, 6 BDss, human BD (hBD)-1 (2), hBD-2 (3), hBD-3 (4,5), hBD-4 (6), hBD-5 and hBD-6 (7) have been identified and characterized in humans. hBD-2 is expressed in a wide range of cell types, such as epithelial cells, keratinocytes and monocytes/macrophages $(8,9)$. It is expressed rarely or lowly under normal circumstances, and is upregulated in response to infectious and inflammatory stimuli through multiple signaling pathways, such as the $\mathrm{NF}-\kappa \mathrm{B}$ pathway $(10,11)$. Previous studies have indicated that BD2 has multiple functions in the immune system, including antibacterial activity (12-14), connection between epithelial innate and adaptive immunity $(15,16)$, as well as chemotactic function $(16,17)$.

ATP is a well-known energy source inside cells, it also functions as an essential messenger between cells. Activation of $\mathrm{P} 2$ receptors, $\mathrm{P} 2 \mathrm{X}$ and $\mathrm{P} 2 \mathrm{Y}$, by ATP may initiate the release of sodium and calcium ions, producing different cellular effects (18). ATP has a wide range of functions in the human body, including the development of pain, the heart and blood vessel disorders, secretion of digestive enzymes, as well as tumor-killing effects (18). In addition, ATP serves an important role in inflammation and infection. ATP activation of the $\mathrm{P} 2 \mathrm{X} 7$ receptor results in the processing and secretion of mature interleukin (IL)-1 $\beta$, which is a potent cytokine capable of inducing inflammation $(19,20)$. Moreover, active ATP release and adenosine receptor signaling are required for activation of the NLR pyrin domain containing 3 (NLRP3) inflammasome that is a major component of the innate immune system (21). Nonetheless, little is known regarding the relationship between BD2 and ATP, as well as their roles in the acute pneumonia of rats.

In the present study, the authors evaluated the impact of ATP on the expression of rat BD-2 (rBD-2) in a time-dependent manner, as well as their protective effect in the acute pneumonia of rat caused by Pseudomonas aeruginosa (PA) (Xinjiang Uygur Autonomous Region Food and Drug Administration, Urumqi, China). The completion of the study provides some novel findings on rBD-2 in acute pneumonia which will be useful to guide further investigation and targeted therapy for this disease. 


\section{Materials and methods}

Animal housing and treatment. Given the homology between rBD-2 and hBD-2, such as 6 cysteine and other lysine and arginine residues (22), the rat was chosen as a model to study the function of hBD-2 in vivo. BALB/c rats (4-6 weeks old, male/female ratio, 1:1; 20-30 g), provided by Medical School of Tongji University (Shanghai, China), were housed under controlled conditions. Procedures involving animals and their care were approved in accordance with the guidelines of the Experimental Animal Ethics Committee of Medical School of Tongji University (Shanghai, China; no. 2010-1-1). A total of 60 rats were randomly divided into treatment and control groups with 30 rats in each. A control group was administrated with normal saline at $250 \mu \mathrm{l} / 100 \mathrm{~g}$ body weight, treatment group was injected with ATP at $0.12 \mathrm{mg} / 10 \mathrm{~g}$ body weight through the tail vein. Rats were sacrificed at 12 , 24 and $36 \mathrm{~h}$, respectively after treatment, and the lung tissues were isolated from each rat and stored in liquid nitrogen.

Determination of $r B D-2$ mRNA in rat lungs by RT-qPCR. Total RNA was isolated from the whole lung tissue using TRIzol reagent (Invitrogen; Thermo Fisher Scientific, Inc., Waltham, MA, USA) and reversely transcribed into cDNA using M-MLV Reverse Transcriptase (Takara Bio, Inc., Otsu, Japan). The following primers were used for PCR amplification of rBD-2: Forward, 5'-GAACTTGACCACTGCCAC ACC-3'; and reverse, 5'-GCTCTAGATTATCATTTCATG TACTTGCACC- 3 '. $\beta$-actin was used as a reference to normalize rBD-2 mRNA expression levels using the $2^{-\Delta \Delta C q}$ method (23). The RT-qPCR primers used for $\beta$-actin in the present study were: Forward, 5'-AACAGTCCGCCTAGA AGCAC-3'; andreverse,5'-GGTTGACATCCGTAAAGACC-3'. Each RNA sample was run in triplicate. PCR parameters were set as follows: 39 cycles of denaturation at $95^{\circ} \mathrm{C}$ for $20 \mathrm{sec}$, annealing at $59^{\circ} \mathrm{C}$ for $30 \mathrm{sec}$ and extension at $72^{\circ} \mathrm{C}$ for $30 \mathrm{sec}$.

Establishment of acute pneumonia model of rat, animal grouping and treatment. Rats were randomly divided into four treatment groups and one control group, with eight rats each. Rats were anesthetized with ether, $1 \mathrm{~cm}$ skin incisions were made along the middle of the mouse's neck, and muscle tissues were bluntly dissected exposing the trachea and thyroid. A total of $0.2 \mathrm{ml}$ PA $\left(6 \times 10^{8} \mathrm{CFU} / \mathrm{ml}\right.$, Xinjiang Uygur Autonomous Region Food and Drug Administration) was injected into each rat trachea in treatment groups, while, the control group was injected with the same dose of sterile phosphate buffered saline, then incisions were sutured. After three days, treatment groups were divided into four different groups: PA infected group, group treated with ATP at $16 \mathrm{mg} / \mathrm{kg}$ or cephalosporins at $0.4 \mathrm{~g} / \mathrm{kg}$ through the tail vein, group treated with both ATP at $16 \mathrm{mg} / \mathrm{kg}$ and cephalosporins at $0.4 \mathrm{~g} / \mathrm{kg}$ through tail vein. Rats were sacrificed $24 \mathrm{~h}$ following treatment, lung tissues and serum were collected and stored in liquid nitrogen for subsequent experiments.

Pathological examination. The grouping and treatment were the same as described above, lung tissues were isolated from rats $24 \mathrm{~h}$ following ATP and cephalosporin intervention. Fresh lung specimens were fixed in $4 \%$ paraformaldehyde, embedded in paraffin, cut and heated, and subjected to hematoxylin and eosin (H\&E) staining. The morphological changes of H\&E-stained tissues were analyzed by Leica digital microscopy.

Immunohistochemistry. Formalin-fixed, paraffin-embedded tissue sections of lung tissues were obtained from treatment and control groups as described above in animal grouping and treatment. The expression of rBD-2 was detected following the immunohistochemistry protocol of Sigma-Aldrich; Merck KGaA (Darmstadt, Germany). The sections were incubated with primary rabbit polyclonal antibody rBD-2 (YY3068R; Santa Cruz Biotechnology, Inc., Dallas, TX, USA) at 1:200 dilution overnight at $4^{\circ} \mathrm{C}$ and secondary antibody [SP9000D; DAB Detection kit (Streptavidin-biotin); ZSGB-BIO, Beijing, China] for another $2 \mathrm{~h}$ at room temperature. Finally, visualization of the sections was conducted and images were taken with a Leica confocal laser scanning microscope (Leica Microsystems, Wetzlar, Germany).

Determination of IL- 6 and tumor necrosis factor (TNF)- $\alpha$ expression in lung tissues and peripheral blood. At $24 \mathrm{~h}$ following ATP and cephalosporin intervention, rats from control and treatment groups were sacrificed and lung tissues were isolated, centrifuged at 2,045 $\mathrm{x}$ g for $20 \mathrm{~min}$ at room temperature followed by collection of supernatants. The peripheral blood samples were also collected. IL- 6 and TNF- $\alpha$ expression was evaluated using ELISA assay kits in accordance with the instructions (Invitrogen; Thermo Fisher Scientific, Inc.).

Statistical analyses. Data were presented as mean \pm standard deviation. Student's t-test or SNK-q test was used to determine the statistical significance between each two groups, differences among multiple groups were analyzed using an analysis of variance (ANOVA). The SNK-q test was used for multiple comparisons. $\mathrm{P}<0.05$ was considered to indicate a statistically significant difference.

\section{Results}

ATP enhanced expression of $r B D-2$ mRNA in rat lungs. Expression of rBD-2 in lung tissues of rats in response to ATP has not yet been investigated. Therefore, the authors determined induction of rBD-2 expression by ATP in the lung tissues of rat. RT-qPCR was conducted to analyze the expression pattern of rBD-2 following ATP stimulation. The expression of rBD-2 gene was upregulated in ATP-treated groups at $12 \mathrm{~h}(0.5921 \pm 0.3007$ vs. $0.9029 \pm 0.3136, \mathrm{P}=0.001$, t-test), $24 \mathrm{~h}(0.6031 \pm 0.2943$ vs. $1.3867 \pm 0.3011, \mathrm{P}<0.001$, t-test $)$ and $36 \mathrm{~h}(0.5273 \pm 0.3211$ vs. $1.0912 \pm 0.2591, \mathrm{P}<0.001$, t-test; Fig. 1). It increased greatly at $12 \mathrm{~h}$, reached highest peak at $24 \mathrm{~h}$ and gradually declined by $\sim 20 \%$ at $36 \mathrm{~h}$ following ATP treatment, however, significant differences of the expression of rBD-2 were observed between each control and treatment group at 12,24 and $36 \mathrm{~h}$. Therefore, the authors confirmed that ATP could upregulate rBD-2 mRNA expression in rat lungs.

ATP increases expression of $r B D-2$ protein in rat lungs. As expression of rBD-2 mRNA was upregulated by ATP in rat 


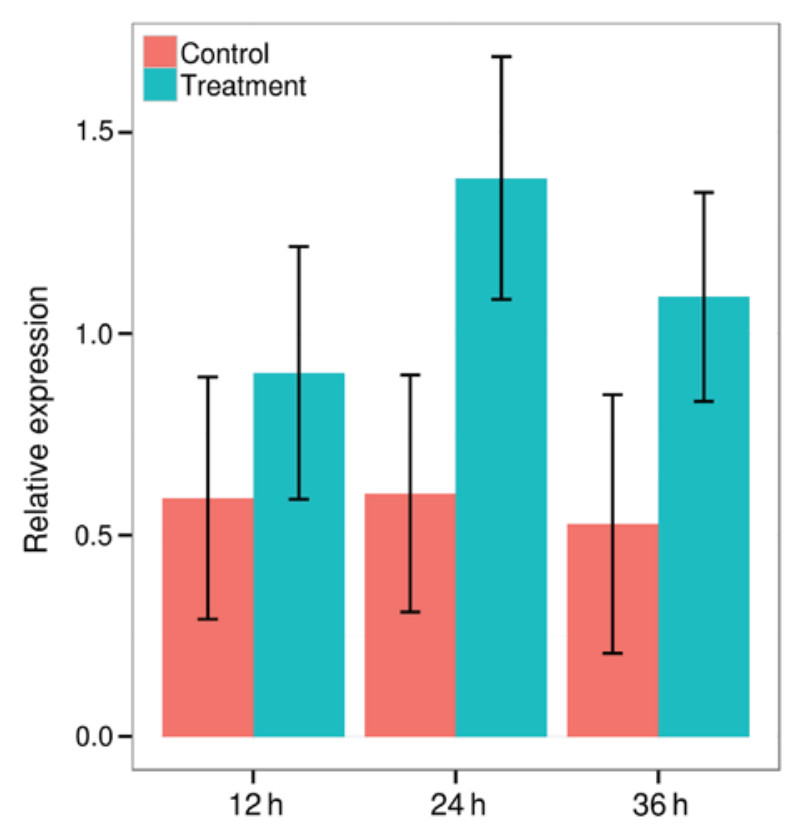

Figure 1. $\beta$-defensin-2 mRNA expression measured by reverse transcription-quantitative polymerase chain reaction in rat lungs. Data are presented as mean \pm standard deviation.

lungs, the next question concerned whether ATP promotes the production of rBD-2 protein in vivo. In the present study, the authors reported that the expression of the rBD-2 protein was slightly increased in the PA infected group, an enhanced expression of the rBD-2 protein was observed in the ATP or cephalosporin treatment group and the cephalosporin and ATP treatment group, in comparison with that in PA infected group and control group, suggesting ATP could induce rBD-2 expression at both mRNA and protein levels in rat lungs (Fig. 2).

ATP alleviates histological changes in rat lungs. Microcopy indicated that alveolar and interstitial lung structures were normal, alveolar inflatable was good, no exudation of red blood cells was observed, part of bronchial and alveolar walls were infiltrated with a small amount of inflammatory cells in the lung tissues of the control group. The PA infected group presented alveolar wall edema, infiltration of a large number of inflammatory cells (neutrophils and lymphocytes) on bronchial and alveolar walls, red blood cells and cellulose exudation in the alveolar space. ATP or ceftazidime intervention groups presented an improved lung edema, less inflammatory cell infiltration, thicker partial alveolar wall and a small amount of red blood cells as compared with the PA infected group. The results demonstrated that ceftazidime, ATP and ceftazidime + ATP treatment groups improved the histological destruction of lung tissues caused by PA (Fig. 3).

ATP decreases expression of TNF- $\alpha$ and IL-6 levels in rat lungs. Following this, the authors next investigated mechanisms by which enhancement of rBD-2 by ATP presented a beneficial effect on the PA infection in rat lungs. In order to clarify whether $\mathrm{rBD}-2$ regulated the secretion of proinflammatory cytokines, IL- 6 and TNF- $\alpha$ expression was analyzed by ELISA. Significant differences of IL-6 and TNF- $\alpha$ expression were identified in both lung and serum among five groups (F: 12.4864-28.3971, v=4, P=0.0000, ANOVA), PA induced a significant increase in TNF- $\alpha$ and IL-6 expression levels in rat lungs and serum of treatment groups as compared with the control group (TNF- $\alpha, 44.1250 \pm 6.6235$ vs. 33.9750 \pm 1.0403 ; IL-6, $125.2813 \pm 38.7227$ vs. $11.8438 \pm 4.2075$ in serum; TNF- $\alpha$, $59.3000 \pm 17.1713$ vs. $17.5438 \pm 3.4582$; IL-6, $47.3875 \pm 12.8895$ vs. $25.7250 \pm 3.3139$ in rat lung, $\mathrm{P}<0.05$ for all cases, $\mathrm{SNK}-\mathrm{q}$ test). Moreover, IL-6 and TNF- $\alpha$ expression in the rat lung and serum was reduced in ceftazidime, ATP and ceftazidime + ATP treatment groups relative to the PA-infected group $(\mathrm{P}<0.05$ for all cases, $\mathrm{SNK}-\mathrm{q}$ test). No significant difference was observed for TNF- $\alpha$ expression in serum and IL-6 in lungs among ceftazidime, ATP and ceftazidime + ATP treatment groups ( $\mathrm{P}>0.05$ for all cases, SNK-q test). However, the ceftazidime + ATP treatment group presented a decreased expression of TNF- $\alpha$ in lungs and IL- 6 in serum relative to ceftazidime or ATP treatment groups $(\mathrm{P}<0.05$ for all cases, SNK-q test; Fig. 4).

\section{Discussion}

There has been an increasing body of evidence that ATP serves a protective role in the immune system. ATP promotes a wide range of epithelial responses through the activation of $\mathrm{P} 2 \mathrm{X}$ and $\mathrm{P} 2 \mathrm{Y}$ receptors in response to infectious stimuli and injuries. For instance, ATP mediates the activation of the NADPH oxidase DUOX1 through the P2Y receptor, phospholipase $\mathrm{C}$ and intracellular calcium signaling in the airway epithelium, leading to the activation of ERK1/2 and $\mathrm{NF}-\kappa \mathrm{B}$ pathways, IL-8 release and the production of $\mathrm{H}_{2} \mathrm{O}_{2}$ in response to bacterial stimulations or tissue injury $(24,25)$. In addition, ATP modulates the activities of the NLRP3 inflammasome during bacterial infection by activation of the purinergic receptor $\mathrm{P} 2 \mathrm{X} 7$, resulting in IL-1 $\beta$ maturation and secretion of chemokines $(26,27)$. Here, believed to be for the first time, the authors reported that ATP upregulated the expression of rBD-2 mRNA and enhanced the production of rBD-2 protein in response to the bacterial stimulation of PA in rat lungs. A possible mechanism underlying this process is that ATP activates the NF- $\mathrm{B}$ pathway, which is critical to the production of rBD-2 $(11,28)$ through either the $\mathrm{P} 2 \mathrm{X}$ or $\mathrm{P} 2 \mathrm{Y}$ receptor, however, further studies are still required in the future.

In addition, enhanced rBD-2 expression by ATP reduced inflammatory damage was caused by PA in lung tissues, indicating that $\mathrm{rBD}-2$ ameliorates the infection of PA. These findings are consistent with studies conducted by Wu et al (12) and $\mathrm{Hu}$ et al (29). The primary reasons may lie in the antibacterial function of increased rBD-2 and its regulation of inflammatory factors during bacterial infection and inflammation. Therefore, the authors analyzed the secretion of cytokines, TNF- $\alpha$ and IL- 6 following stimulation of ATP and ceftazidime. It was identified that PA infection significantly increased pro-inflammatory factors, such as TNF- $\alpha$ and IL-6 in the rats, and overexpression of rBD-2 by ATP inhibited the increase of these inflammatory factors. These results are in line with a previous report by Wu et al (12), indicating that rBD-2 accelerated the weakening process of inflammation.

In summary, these results demonstrated that ATP induces rBD-2 mRNA and rBD-2 protein expression in rat lungs and 


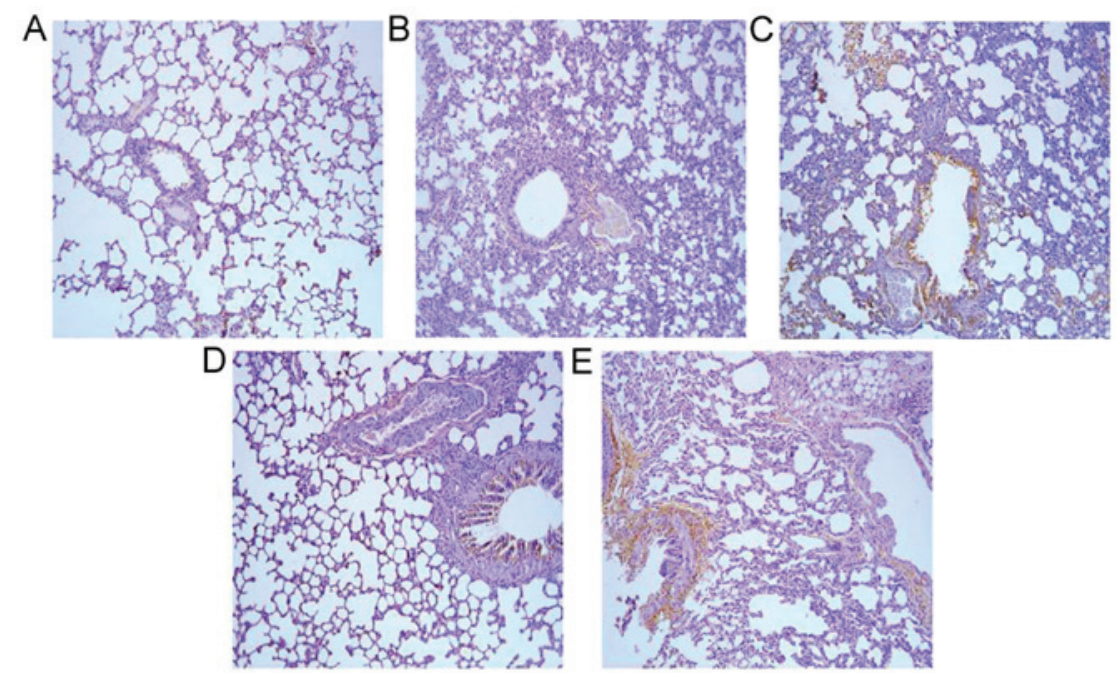

Figure 2. Expression of $\beta$-defensin-2 protein of rat lungs detected by immunohistochemistry in different groups (magnification, x200): (A) Control group treated with normal saline, (B) Pseudomonas aeruginosa infected group, (C) group treated with ATP,(D) group treated with ceftazidime, and (E) group treated with ceftazidime and ATP.

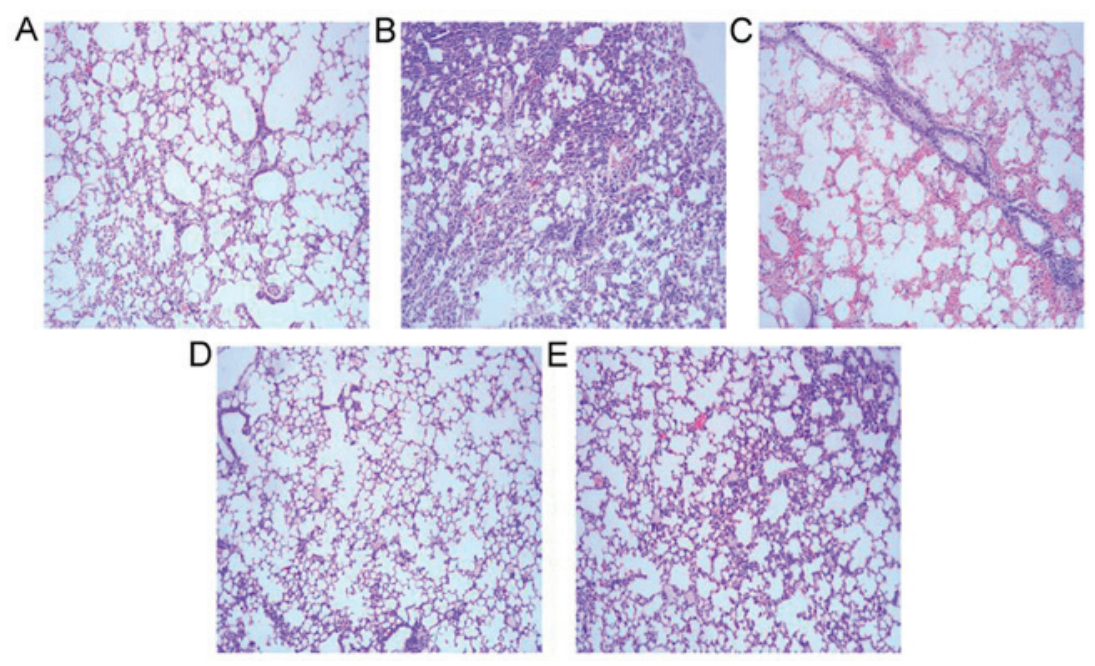

Figure 3. Histopathological changes of rat lungs in different groups (magnification, x200): (A) Control group treated with normal saline, (B) Pseudomonas aeruginosa infected group, (C) group treated with ATP, (D) group treated with ceftazidime, and (E) group treated with ceftazidime and ATP.

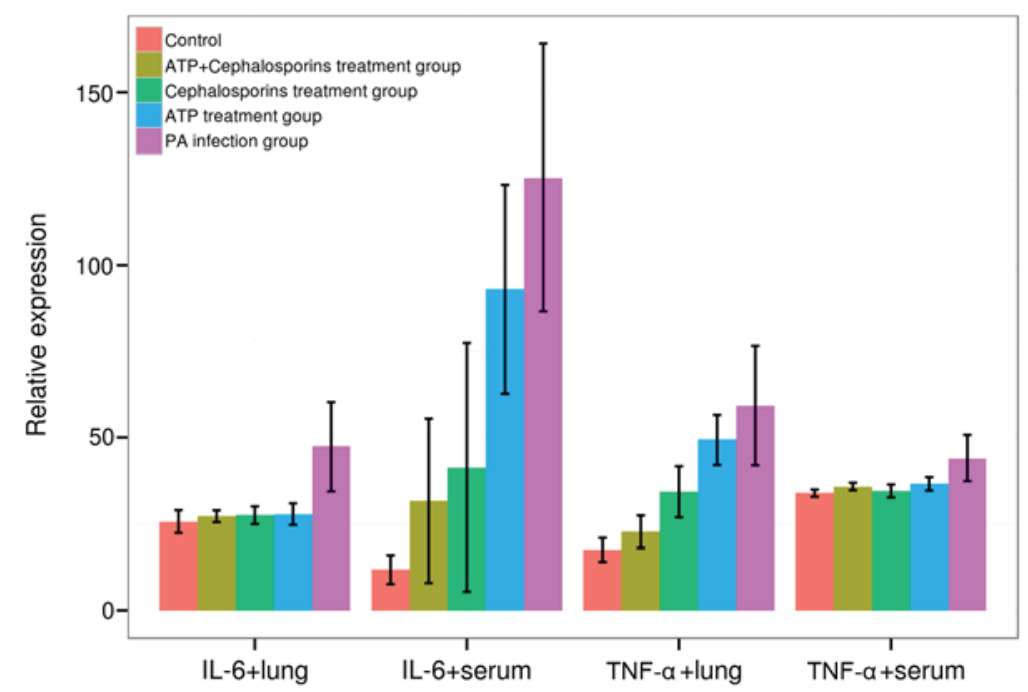

Figure 4. Changes of TNF- $\alpha$ and IL-6 protein production measured by ELISA in rat lung and serum. Data are presented as mean \pm standard deviation. TNF- $\alpha$, tumor necrosis factor- $\alpha$; IL, interleukin. 
decreases the expression of proinflammatory cytokines TNF- $\alpha$ and IL-6, suggesting ATP has protective effects against infection of PA. These results may provide a better understanding of the therapeutic values of ATP and hBD-2 in infectious diseases.

\section{Acknowledgements}

The present study was made possible with financial support from Youth Foundation of Shanghai Municipal Health Bureau (grant no. 20124y113) to H.L.

\section{References}

1. Schutte BC and McCray PB Jr: [beta]-defensins in lung host defense. Annu Rev Physiol 64: 709-748, 2002.

2. Bensch KW, Raida M, Mägert HJ, Schulz-Knappe $P$ and Forssmann WG: hBD-1: A novel $\beta$-defensin from human plasma. FEBS Lett 368: 331-335, 1995.

3. Harder J, Bartels J, Christophers E and Schröder JM: A peptide antibiotic from human skin. Nature 387: 861, 1997.

4. Harder J, Bartels J, Christophers E and Schröder JM: Isolation and characterization of human $\beta$-defensin-3, a novel human inducible peptide antibiotic. J Biol Chem 276: 5707-5713, 2001.

5. Jia HP, Schutte BC, Schudy A, Linzmeier R, Guthmiller JM, Johnson GK, Tack BF, Mitros JP, Rosenthal A, Ganz T, et al: Discovery of new human beta-defensins using a genomics-based approach. Gene 263: 211-218, 2001.

6. Yanagi S, Ashitani J, Ishimoto H, Date Y, Mukae H, Chino N and Nakazato M: Isolation of human beta-defensin-4 in lung tissue and its increase in lower respiratory tract infection. Respir Res 6: $130,2005$.

7. Yamaguchi Y, Nagase T, Makita R, Fukuhara S, Tomita T, Tominaga T, Kurihara $\mathrm{H}$ and Ouchi Y: Identification of multiple novel epididymis-specific beta-defensin isoforms in humans and mice. J Immunol 169: 2516-2523, 2002.

8. Lehrer RI, Lichtenstein AK and Ganz T: Defensins: Antimicrobial and cytotoxic peptides of mammalian cells. Annu Rev Immunol 11: 105-128, 1993.

9. Ganz T: Defensins: Antimicrobial peptides of innate immunity. Nat Rev Immunol 3: 710-720, 2003.

10. Méndez-Samperio P, Miranda E and Trejo A: Regulation of human $\beta$-defensin- 2 by Mycobacterium bovis bacillus Calmette-Guérin (BCG): Involvement of PKC, JNK, and PI3K in human lung epithelial cell line (A549). Peptides 29: 1657-1663, 2008.

11. Tsutsumi-Ishii Y and Nagaoka I: NF-kappa B-mediated transcriptional regulation of human beta-defensin-2 gene following lipopolysaccharide stimulation. J Leukoc Biol 71: 154-162, 2002.

12. Wu M, McClellan SA, Barrett RP and Hazlett LD: Beta-defensin-2 promotes resistance against infection with $\mathrm{P}$. aeruginosa. J Immunol 182: 1609-1616, 2009.

13. Dalcin D and Ulanova M: The Role of Human Beta-Defensin-2 in Pseudomonas aeruginosa Pulmonary Infection in Cystic Fibrosis Patients. Infect Dis Ther 2: 159-166, 2013.

14. Guaní-Guerra E, Negrete-García MC, Montes-Vizuet R, Asbun-Bojalil $\mathrm{J}$ and Terán LM: Human $\beta$-defensin-2 induction in nasal mucosa after administration of bacterial lysates. Arch Med Res 42: 189-194, 2011.
15. Krisanaprakornkit S, Kimball JR, Weinberg A, Darveau RP, Bainbridge BW and Dale BA: Inducible expression of human beta-defensin 2 by Fusobacterium nucleatum in oral epithelial cells: Multiple signaling pathways and role of commensal bacteria in innate immunity and the epithelial barrier. Infect Immun 68: 2907-2915, 2000.

16. Yang D, Chertov O, Bykovskaia SN, Chen Q, Buffo MJ, Shogan J, Anderson M, Schröder JM, Wang JM, Howard OM, et al: Beta-defensins: Linking innate and adaptive immunity through dendritic and T cell CCR6. Science 286: 525-528, 1999.

17. Boniotto M, Jordan WJ, Eskdale J, Tossi A, Antcheva N, Crovella S, Connell ND and Gallagher G: Human beta-defensin 2 induces a vigorous cytokine response in peripheral blood mononuclear cells. Antimicrob Agents Chemother 50: 1433-1441, 2006.

18. Khakh BS and Burnstock G: The double life of ATP. Sci Am 301: 84-92, 2009.

19. Stoffels M, Zaal R, Kok N, van der Meer JW, Dinarello CA and Simon A: ATP-Induced IL-1 $\beta$ Specific Secretion: True Under Stringent Conditions. Front Immunol 6: 54, 2015.

20. Ferrari D, Chiozzi P, Falzoni S, Dal Susino M, Melchiorri L, Baricordi OR and Di Virgilio F: Extracellular ATP triggers IL-1 beta release by activating the purinergic $\mathrm{P} 2 \mathrm{Z}$ receptor of human macrophages. J Immunol 159: 1451-1458, 1997.

21. Baron L, Gombault A, Fanny M, Villeret B, Savigny F, Guillou N, Panek C, Le Bert M, Lagente V, Rassendren F, et al: The NLRP3 inflammasome is activated by nanoparticles through ATP, ADP and adenosine. Cell Death Dis 6: e1629, 2015.

22. Jia HP, Mills JN, Barahmand-Pour F, Nishimura D, Mallampali RK, Wang G, Wiles K, Tack BF, Bevins CL and McCray PB Jr: Molecular cloning and characterization of rat genes encoding homologues of human beta-defensins. Infect Immun 67: 4827-4833, 1999.

23. Livak KJ and Schmittgen TD: Analysis of relative gene expression data using real-time quantitative PCR and the 2(-Delta Delta C(T)) Method. Methods 25: 402-408, 2001.

24. Boots AW, Hristova M, Kasahara DI, Haenen GR, Bast A and van der Vliet A: ATP-mediated activation of the NADPH oxidase DUOX1 mediates airway epithelial responses to bacterial stimuli. J Biol Chem 284: 17858-17867, 2009.

25. de Oliveira S, López-Muñoz A, Candel S, Pelegrín P, Calado Â and Mulero V: ATP modulates acute inflammation in vivo through dual oxidase 1-derived $\mathrm{H} 2 \mathrm{O} 2$ production and $\mathrm{NF}-\kappa \mathrm{B}$ activation. J Immunol 192: 5710-5719, 2014

26. Xiang Y, Wang X, Yan C, Gao Q, Li SA, Liu J, Zhou K, Guo X, Lee W and Zhang Y: Adenosine-5'-triphosphate (ATP) protects mice against bacterial infection by activation of the NLRP3 inflammasome. PLoS One 8: e63759, 2013.

27. Di Virgilio F: Liaisons dangereuses: P2X(7) and the inflammasome. Trends Pharmacol Sci 28: 465-472, 2007.

28. Wada A, Ogushi K, Kimura T, Hojo H, Mori N, Suzuki S, Kumatori A, Se M, Nakahara Y, Nakamura M, et al: Helicobacter pylori-mediated transcriptional regulation of the human beta-defensin 2 gene requires NF-kappaB. Cell Microbiol 3: 115-123, 2001.

29. Hu Q, Zuo P, Shao B, Yang S, Xu G, Lan F, Lu X, Xiong W, $\mathrm{Xu} \mathrm{Y}$ and Xiong S: Administration of nonviral gene vector encoding rat beta-defensin-2 ameliorates chronic Pseudomonas aeruginosa lung infection in rats. J Gene Med 12: 276-286, 2010. 